\title{
EL MARC INSTITUCIONAL: ESTRUCTURA ORGANITZATIVA I NORMATIVA
}

\author{
Jaume Vallverdú \\ DEPARTAMENT D'ANTROPOLOGIA SOCIAL I FILOSOFIA \\ UNIVERSITAT ROVIRA I VIRGILI. TARRAGONA.
}

\section{Introduccí}

Per a la confecció d'aquest article s'han seleccionat tres de les vuit unitats religioses que integren la mostra d'anàlisi del present dossier: el Moviment Hare Krisna, l'Orde Benedictí i els Testimonis de Jehovà. No caldria ni dir que es tracta de confessions força diferenciades quant a sistema de creences, alhora que ubicades en moments històrics i contextos sòcio-culturals força espars. L'Associació per a la Consciència de Krisna, d'arrel religiosa oriental-hindú $i$ inspirada en la filosofia vèdica, arriba a Occident a la segona meitat d'aquest segle de la mà del que ha estat el seu darrer gran mestre espiritual: Srila Prabhupada; el monaquisme benedict́ té el seu orígen a l'Umbria italiana del segle VI en la figura de Benet de Núrsia i, com és ben sabut, s'inscriu en el marc general de l'Església catolica; per últim, els Testimonis de Jehovà, fundats l'any 1870 als Estats Units per Taze Russell, són coneguts com una confessió cristiana de caràcter mil·lenarista sorgida de la lliure interpretació biblica.

L'objectiu fonamental de l'escrit és analitzar part de la naturalesa constitutiva d'aquesta "diversitat espiritual" mitjançant la comparació integrada dels sistemes organitzatius i normatius de cadascuna de les instàncies esmentades. A tal efecte, han estat triades considerant, a més del factor heterogeneïtat, el fet que d'alguna manera esdevinguin models paradigmàtics dels diferents graus de legitimació que la nostra societat atribueix a la pluralitat religiosa.

A partir d'aquí, tres temes semblen d'especial centralitat per encetar la reflexió empírica al voltant de la construccí́ i reproducció de les pautes ordenatives institucionals i, en un marc més ampli, dels processos de legitimació o deslegitimació dels diferents sistemes de fe. Aquests temes serien:

a) La correlació entre la diversitat objectiva de les instàncies religioses mencionades i les recurrències en forma $i$ contingut de les seves estructures organitzatives i normatives.

b/ Els components de base social-institucional que fonamenten l'ordenacio dels diferents codis culturals, informadors, entre altres, dels mecanismes de formació d'identitat i sociabilitat religiosa. cl La simbiosi cognició individual-marc normatiu institucional i l'enduriment de nexes primaris de relació a través de l'adhesió lleial a un "sistema de símbols" que tendeix a "establir vigorosos, penetrants i duraders estats anímics i motivacionals entre els homes, formulant concepcions d'un ordre general d'existència i revestint aquestes concepcions amb una aureola d'efectivitat tal que els estats anímics i motivacionals semblin d'un realisme únic" (Geertz, 1989:89).

Sobre aquestes premisses, primerament, s'intenta esbossar l'articulació institucional global de cada un dels grups escollits, per tal d'observar-ne els paral-lelismes formals i funcionals. A continuació, en el que constituiria el gruix informatiu de l'article, es procedeix a la descripció 
comparativa dels seus respectius documents normatius: Cómo llegar a ser vaisnava (Hare Krisna), La Regla de Sant Benet (Orde Benedictina) i Organizados para efectuar nuestro ministerio (Testimonis de Jehovà). Val a dir, que donada la brevetat de la primera font al-ludida, s'han utilitzat com a materials de suport el text sagrat bàsic del Moviment Hare Krisna, el BhagavadGita, tant en la seva versió oficial (Prabhupada, 1978) com sintetitzada (Ramacharaka, 1991) i de manera molt puntual l'article de Pozuelo, F.G. (1990) "Hare Krisna: perspectiva sociológica". Finalment, el darrer apartat de l'escrit, pretén llençar algunes idees a cadascun dels temes especificats, tot cercant-hi els elements explicatius principals.

\section{Estructura organitzativa: institucions $i$ jerarquia}

Abans de passar a analitzar la realitat comunitària a petita escala, que és on els cànons de cada manifestació religiosa tenen aplicació més directa, caldria potser fer una breu síntesi del marc organitzatiu general en què aquests cànons s'insereixen i a través del qual adquireixen sentit.

El model d'organització global dels àmbits institucionals objecte de comparació es caracteritza per basar-se en una jerarquia solidament estructurada que va des de les altes instàncies fins als col-lectius locals. Els diferents estaments que conformen aquesta jerarquia tenen expressió formal en una sèrie d'organismes de gestió burocràtico-administrativa/espiritual i estan sempre condicionats per la supervisió dels esgraons immediatament superiors. Es tracta, en conjunt, d'un sistema d'estratificació vertical que s'amotlla formalment i funcionalment a l'espai geogràfic en què el grup religiós té implantació amb l'objecte d'exercir un control adequat del seu desenvolupament. Aixi, la cohesió organitzativa es construeix a partir de la correspondència directa entre el successiu fraccionament territorial d'assentament $i$ la distribució subordinada de càrrecs institucionals, quedant segellada des de la cúpula de govern.

En el Moviment Hare Krisna distingim entre dues línies superposades d'autoritat procedents d'una cadena de deixebles molt antiga que segons els devots arrenca de la mateixa divinitat Sri Krisna-Caitanya: una línia "organitzativa", establerta per la institució amb l'objecte de sustentar el propi funcionament, i una línia "espiritual" (Ashrama), d'origen diví. A la primera, tot seguint l'esgraonament jeràrquic, tenim: GBC, secretaris regionals, presidents nacionals i presidents de temple; a la segona, Sannyasa-swami (vida d'ermità o renúncia), Vanaprastha (vida retirada per deslligar-se dels vincles terrenals), Grihasta (vida matrimonial i de treball actiu) i Brahamacari (disciplina i educació en celibat).

El Consell Mundial o GBC (Governing Body Commision) és l'organisme d'autoritat màxim de l'Associació Internacional per a la Consciència de Krisna (ISKCON) i opera a nivell mundial. Els seus membres (mestres espirituals iniciats pel propi fundador) tenen assignades sota responsabilitat diferents zones del món $\mathrm{i}$ han de viatjar contínuament pels temples per comprovar que s'hi segueixen els principis espirituals i controlar el seu correcte funcionament administratiu. Aconsellen les entitats de les seves àrees $\mathrm{i}$ informen els respectius presidents sobre les decisions preses per la Comissió de Govern, convocada anyalment a Mayapur (India). Els presidents dels diversos centres, per la seva banda, es reuneixen una vegada a l'any a fi i efecte de reprendre i acceptar democràticament aquestes conclusions.

\footnotetext{
${ }^{1}$ Representants de la línia espiritual poden formar part de la línia organitzativa i, al seu torn, representants de b línia organitzativa ocupen una determinada situació dins l'ordre espiritual general. Els swamis i/o mestres espirituals són especialment respectats i considerats. Poden ocupar o no alts càrrecs organitzatius (per exemple, ser membres de la Comissió de Govern) al mateix temps que representen un alt càrrec espiritual, però, en qualsevol cas, el seu consell i opinió sempre té molt pes. Els primers reben el titol de "Su Santidad"; els segons el de "Su Divina Gracia".
} 
Els mestres espirituals del Consell Mundial tenen una funció general de supervisió ${ }^{2}$, si bé a efectes pràctics immediats han de deixar que siguin els presidents dels temples els qui condueixin el "projecte". Quan les zones assignades a aquests alts càrrecs són molt grans i se'n fa difícil el control, poden ser inspeccionades sectorialment per secretaris regionals que actuen "como si fueran los ojos del miembro del GBC, y depende de la cuerda que el GBC les dé van a hacer más o menos, van a tomar decisiones de más o menos envergadura y otras decisiones las van a consultar" (H., 22-X-92). Pel contrari, si no tenen massa extensio, el membre del Consell Mundial pot tractar directament els assumptes de l'Associació amb els presidents nacionals.

En conjunt, són diferents càrrecs institucionals els que es distribueixen la supervisió espaial. Així, les diferents unitats territorials (zona, regí i nació) queden representades per una autoritat concreta i sota l'observança regular dels mestres espirituals. Dins l'àmbit nacional, els temples (urbans o en forma de granja agrícola) constitueixen la forma comunitària primordial Hare Krisna.

En el cas de l'Església catòlica, tenim també una societat estamentalment constituĩda. Està organitzada en una estructura pública i segons un principi de subordinació entre els diferents organs que la componsen i té el seu nucli originari en el Vaticà. Al seu si, com a branca del monaquisme cristià d'occident, l'Orde benedictí reprodueix l'esgraonament vertical pel que fa a distribució geogràfica i responsabilitats dels diferents càrrecs a partir del seu propi nucli capdavanter $\mathrm{i}$ alhora punt d'enllaç amb la Santa Seu, la Confederació. Aquesta, encapçalada per l'abat primat, aplega les vint-i-una congregacions existents, dirigides per un abat president. Cadascuna, d'un abast geogràfic de tipus nacional/estatal, està formada per diferents províncies, les quals disposen dels seus respectius superiors i són períodicament supervisades per l'abat president i els visitadors. Acabant la cadena, els monestirs, amb l'abat de comunitat corresponent, representen la instància primària del món benedictí.

A nivell d'interlocució, se segueix igualment el conducte jeràrquic: l'abat primat presideix l'orde i canalitza el diàleg amb el Vaticà; els abats presidents es reuneixen amb ell dues vedades l'any amb la finalitat de consensuar les línies directrius del món benedictí; els visitadors provincials tenen també dues reunions anyals amb l'abat president i l'ajuden en la seva tasca de supervisió canònica; finalment, cada monestir disposa del seu propi abat com a màxima autoritat, que, al seu torn, té en l'esmentat abat immediatament superior la seva comunicació més directa.

Per últim, la Congregació Mundial Unida dels Testimonis de Jehovà "está edificada alrededor del nucleo de los que han sido ungidos mediante espíritu" (1983:25), és a dir, dels integrants de l'anomenat Cos Governant. Concentrat simbolicament en aquest nucli, un conducte global d'organització al qual el fidel s'ha de sotmetre, assegura la cohesió institucional ${ }^{3}$. A partir del model teocràtic, tota la vida del moviment s'estructura en base a una estricta jerarquia. Déu ha escollit un petit nombre d' "íntims", "experts" i "fidels" per formar un cos de govern visible. Des d'aquest fins als grups locals hi ha un descens ordenat d'organismes, càrrecs i funcions.

Els Superintendents de zona, membres del "Cos Governant", són també en aquest cas els encarregats de supervisar els amplis espais geogràfics en què el grup té implantació i a partir dels quals s'articula la gestió de la resta d'instàncies. A continuació, tot seguint l'esgraonament vertical,

${ }^{2}$ El fundador del Moviment digué dels integrants d'aquest organisme de govern que "eran como los perros guardianes de la Asociacion" (H., 22-X-92).

3 -Toda persona de la congregación reconoce el mando que Dios emplea para ejercer el control teocrático. Las congregaciones reconocen la gúa del cuerpo gobernante a medida que éste traza los arreglos de organización para beneficio de todos y obran en conformidad para esta gúa. Aceptan los nombramientos que se hacen de hombres adelantados de edad, o ancianos, para que superentiendan las sucursales, los distritos y circuitos y las congregaciones. Esperan del "esclavo fiel y discreto" alimento espiritual a su debido tiempo. A su vez, tanto el resto, el "esclavo fiel", como su Cuerpo Gobernante $v$ adhieren estrictamente a la jefatura de Cristo, se apegan a los principios biblicos y se someten a la dirección del Espíritu Santo". Organizados para efectuar nuestro ministerio, p. 28. 
el Comitè de sucursal s'ocupa de les diverses responsabilitats relacionades amb l'atenció de l'obra al país o països sota jurisdicció d'una agència o sucursal en particular. El seu objecte fonamental és controlar el desenvolupament de la prèdica per tot el territori assignat i que els organismes que depenen d'aquest funcionin d'acord amb les necessitats del camp. La sucursal, per tant, és la representació de la societat a cada país i l'atén un servidor de sucursal. El districte, per la seva banda, té un caràcter regional i disposa d'un superintendent, que vigila i dirigeix l'esgraó inferior, el circuit. Aquest està regit pel seu corresponent superintendent, encarregat de revisar l'administració, d'orientar proclamadors i dirigents, proposar candidats per a diferents càrrecs, etc. Per últim, la congregació és la cèl-lula local dels Testimonis de Jehovà i té el seu propi servidor president. Si existeix més d'una congregació local, el superintendent de circuit pot recomanar un superintendent de ciutat.

Fins aqué l'estructura organitzativa global. Passem a considerar ara l'articulació jeràrquica comunitària-local. A la "cúpula de direcció" coincideixen uns personatges encarregats de l'administració de la comunitat en general i de la metodització de càrrecs i serveis en particular: el president de temple (Hare Krisna), l'abat (benedictins) i el superintendent president (Testimonis de Jehova). Aquests, com a caps visibles, estan secundaritzats en els tres casos per una persona de confiança: vice-president, prior i secretari o servent auxiliar respectivament. Al seu torn, el Consell de temple (Hare Krisna), els degans (benedictins) ${ }^{4}$ i el Cos d'ancians (Testimonis de Jehovà) són òrgans que realitzen una funció d'assessorament a la direcció, que tenen un paper important en la presa de decisions i en els quals destaquen els mèrits de vida, l'alçada espiritual i l'experiència dels seus membres. D'altra banda, caps de departament, sacerdots (així els anomena la Regla de Sant Benet) ${ }^{5}$ i superintendents de serveis, s'ocupen dels processos de gestió més immediats de la comunitat, tot $i$ romandre sempre subordinats institucionalment $i$ operativament a la consulta de l'autoritat central.

Aquesta autoritat central aglutinadora de poder i responsabilitat esdevé essencial en l'articulació de la vida comunitària. A ella s'ha de professar total obediència i credibilitat, i qualsevol tessitura o decisió individual de certa rellevància passa per la seva valoració $\mathrm{i}$ conformitat. En tots els casos es tracta de persones amb unes característiques i capacitats espirituals superiors i, per tant, especialment preparades per a conduir el "ramat" que els ha estat encomanat pel camí correcte, és a dir, el del coneixement i la salvació. Es per això que se'ls ha de rendir tot el servei i subjecció, doncs del seu consell i guia partirà l'avançada dels fidels. En definitiva, han de ser personatges que representin un model solid a seguir, que facin efectiva la seva autoritat $\mathrm{i}$ que, de cara a la resolució dels assumptes personals més delicats, inspirin plena confiança ${ }^{6}$.

4 A la realitat monàstica actual, Consell de comunitat i Consell de degans constitueixen les dues instancies d'assessorament de l'abat.

${ }^{5}$ A la realitat monàstica actual tindríem la figura del majordom o administrador.

${ }^{6}$ En el Moviment Hare Krisna el president de temple té l'autoritat absoluta dins la comunitat, tot $\mathrm{i}$ que organitzativament, en determinades circumstàncies, hi bagi una intersecció a nivell de prestigi o rang en la representació d'aquesta autoritat entre l'oficialment instituīda i la que s'ofereix per àtica de consideració als deixebles directes del fundador. Perd l'autèntica autoritat individual és la del mestre espiritual, considerat de la següent manera: "representante de Krisna (...) permanece fijo en la verdad absoluta (...) consulta con él sumisamente y ríndele servicio. El, que es una alma perfecta, puede impartirte el conocimiento, porque él ha visto la verdad". Cómo llegar a ser vaisnava, p. 6-7.

"(l'abat) fa les vegades del Crist al monestir, des del moment que designat amb el seu mateix nom, segons diu l'Apostol: heu rebut l'esperit dels fills adoptius que ens fa clamar: Abbà, Pare*. Regla de Sant Benet, p. 17.

"...hombres adelantados en edad o ancianos, para atender al rebaño (...) eran de más edad que otros en sentido espiritual (...) personas que aplican el consejo de la Biblia en todo asunto de la vida (...). Los miembros de la congregación siempre 
Normativament es recalca la importància que correspon a aquests màxims dirigents com a portadors d'autoritat, així com el fet que han de servir d'exemple en tots els ordres de la vida. En qualitat de "tutors avançats" absolutament dedicats a la institució, disposen d'un notable coneixement doctrinal, que apliquen, raonen $\mathrm{i}$ en el qual eduquen, $\mathrm{i}$ han de transmetre amor $\mathrm{i}$ misericòrdia entre els seus deixebles. Com a autoritats instituides, cal que projectin rigor en el seguiment dels cànons regulatius i en l'actitud contemplativa en general. El sentit de l'ordre vital, la disciplina espiritual i el govern d'un mateix contra les adversitats, afavoreix el manteniment del fidel en el camf idoni cap a la perfecció. Sintetitzant: han de ser, d'una banda, moderats, pietosos, considerats, equilibrats, justos, dignes d'estimació i prudents; i d'una altra, disciplinats, rectes, rigorosos, exemplars i conscients de la seva potestat. Tindran ,com a funcions fonamentals les de servir i donar compte?.

La personalitat adequada a aquest càrrec i els compromisos que s'hi associen serà, per tant, aquella que compleixi de paraula $\mathrm{i}$ obra els requisits normatius pel que fa a l'equilibri i solidesa personal i devocional. Els homes que satisfan tot i cadascun dels atributs mencionats són dignes d'imitació i estan capacitats per protegir la comunitat espiritual dels perills que constantment la sotgen.

\section{Estructura normativa: articulació i funcionament intern}

Tot i les variacions infraestructurals i representatives imposades per l'especificitat sòciocultural i religiosa, monestir benedictí i granja agrícola Hare Krisna són espais residencials amb unes característiques bastant similars. S'ubiquen en propietats relativament extenses, allunyades de les poblacions properes (en la línia ideologica de separació respecte a la "mundanalitat"), situades en hàbitats favorables a l'agricultura, amb una arquitectura de grans dimensions, i dotades de zones propícies a la vida ascètica i d'estances ajustades a les necessitats dels diferents serveis de la comunitat. Organitzades per l'autoabastiment i delimitades en sentit físic, han d'evitar al màxim els interessos de sortida a l'exterior dels seus habitants's . Les diverses dependències tant del

deben pensar que pueden hablarles con toda libertad, cuando necesiten ayuda (...) Mediante estos "dones en forma de bombres" Jehová ha hecho excelente provisión para que la congregación sea edificada*. Organizados para efectuar nuestro ministerio, p. 24-24-30-46.

7 El president nacional (i de temple) Hare Krisna, a la pregunta de quina seria la seva principal responsabilitat com a tal afirma: "ver que el ambiente espiritual se mantenga en los centros que hay en España. Lo primero eso, que los miembros espiritualmente funcionen bien dentro de lo posible, aunque luego cada uno tiene su trayectoria individual, no puedes meterte en el corazón de nadie. Pero tratar de ayudar dentro de lo que esté en mi mano a todos los miembros". (H., 27-10-92).

'...que sàpiga que més li pertoca servir que manar (...) que els seus manaments i la seva doctrina difonguin en els cors dels deixebles el llevat de la justícia divina (...) no posi més afany en les coses transitories, terrenals i caduques, sinó que pensi sempre que ha acceptat de governar ànimes, de les quals haurà de donar compte*. Regla de Sant Benet, p. 134-17-21.

"Como imitadores de Jesús deben servir de buena voluntad, con verdaderas ganas y como ejemplos para el rebaño, y tlevar la delantera en el servicio de Jehová (...) tienen que ejercer cuidado especial para no enseñorearse del rebaño de Dios, para no usar su posición de responsabilidad como medio de sacar ventaja egoista, y ni siquiera servir por pensar que están obligados a bacerlo (...) Se hallan en la situación de tener que rendir cuenta en lo que respecta al cuidado de las almas de los que han sido confiados en atención de ellos", Organizados para efectuar nuestro ministerio, p. 29-30-39.

8 "El monestir, si és possible, s'ha d'establir de tal manera que totes les coses necessìries, és a dir, l'aigua, el moli, el forn i els diversos oficis, s'exerceixin a l'interior del monestir, per tal que els monjos no tinguin necessitat de córrer per fora, perquè no convé de cap manera a les seves ànimes*. Regla de Sant Benet, p. 139. 
monestir com de la granja es caracteritzen per la senzillesa i austeritat que predomina en tots els ordres de la vida comunitària; els àmbits sagrats, església i temple respectivament, i els d'importància cultural, com ara la biblioteca, reben una preservació i atenció especial.

El diferent model d'organització general (congregacional) que caracteritza els Testimonis de Jehovà fa que no puguem parlar d'una disposició residencial semblant a les anteriors. Però sí podem fer-ho d'un espai de reuní local específic amb unes finalitats socio-litúrgiques determinades: el Saló del Regne. Es un lloc que segons la normativa dels Testimonis té un propòsit fonamentalment funcional; serveix tant per efectuar l'adoració a la divinitat i diferents cerimonies religioses com per dur a terme les reunions regulars de la congregació $\mathrm{i}$ acollir $\mathrm{i}$ acomodar persones interessades.

En relació amb aixo, cal assenyalar que per al correcte funcionament global de la comunitat i dels seus diferents processos religiosos, és imprescindible l'assignació de diferents serveis als fidels. A través de la distribució de tasques i funcions s'atén el culte i se soluciona el manteniment infraestructural, aspectes sovint inseparables, ja que qualsevol servei "material" per a la comunitat acostuma a tenir un valor "espiritual" incalculable. D'aquesta forma, en tots els casos, i amb independència de la connotació "congregacional" o "monàstica" dels col-lectius que s'analitzen, valor del treball i valor del temps romanen en relació directa amb la pràctica devocional. Aquesta, constitueix l'ocupació central i impregna totalment els paràmetres referencials bàsics de la vida quotidiana del fidel, fent que treball $\mathrm{i}$ temps comunitaris s'organitzin i adquireixin sentit en base a ella.

Una vegada situats en un espai físicament i operativament organitzat, posem ara en relació cànons institucionals amb experiència. I comencem parlant de com s'expressen a nivell normatiu les finalitats i llogres de la vivència espiritual. En les tres unitats religioses d'anàlisi, l'objectiu fonamental de la iniciació és despertar la consciència en la divinitat. Mitjançant la fe, la dedicació i el perfeccionament espiritual progressiu, es tracta de corregir a temps les deficiències humanes derivades del lligam amb les formes materials d'existència i dirigir la conducta al servei exclusiu i amorós a Déu, suportant, si és necessari, els patiments espirituals i/o físics que es puguin derivar del seguiment estricte de la instrucció regulativa9. Tot, amb la mira posada en la "única veritat" i en la recompensa final: l'eternitat de l'ànima en l'ordre just i harmònic del Regne de Déu.

A nivell cosmogònic, s'estableix, de base, una profunda dicotomia món materialmón espiritual. A partir d'aquest model polar de concebre l'existència humana s'insisteix en la necessitat d'abandonar la vida mundana i de dirigir-se cap al camí correcte, el de l'espiritualitat; només així quedaran a un costat ansietats i frustracions de la pròpia vida i milloraran les relacions

Obviament, el monaquisme benedictí dels nostres dies no sols no exclou de forma explícita la comunicació dels monjos amb la vida social general sino que, en molts aspectes, conviu amb aquesta i participa de les seves circumstàncies. Quelcom similar podem dir del Moviment Hare Krisna, tot i que el seu fundador va insistir en la necessitat de desenvolupar granges agrícoles autosuficients on predominés una vida espiritualista en plena harmonia amb la natura i es fugís al màxim del món materialista i dels elements teenologics que produeix.

9 "Mucha virtud y mérito hay en el dominio de sí mismo (...) y los que tal hacen viene a Mi". "El que se abstiene, puede, en algunas ocasiones, verse acometido por un tumultuoso deseo que haga fracasar su resolución, pero sabe que el verdadero Ser es la única Realidad; es dueño de sus sentidos y deseos*."Una vez fija la mente en el verdadero Ser, fuera locura desviarla de su objeto supremo. Si tal ocurriera, refrénala y vuelve a encauzarla en la dirección anterior". BhagavadGita, p. 39-27-50.

"...hi ha un zel bo que allunya dels vicis i porta a Déu i a la vida eterna. Que practiquin, doncs, els monjos, aquest zel amb un amor ferventíssim, és a dir, que s'avancin a honorar-se els uns als altres, que se suportin amb una gran paciència les seves febleses, tant físiques com morals...*. Regla de Sant Benet, p. 174.

-...en la situación (sufrir como cristianos) pudieran estar envueltas varias formas de sufrimiento físico o angustia mental". Organizados para efectuar nuestro ministerio, p. 165. 
en general. La divinitat, a la qual s'ha d'adorar i servir amb constància, proporciona l'aliment espiritual imprescindible per avançar en la fe i la devoció.

Perfeccionament espiritual implica coneixement d'un mateix i de la naturalesa divina. La vida espiritual sempre es presenta com un camí estret i dificultós en un principi, però que s'eixampla a poc a poc gràcies a la perseverança en les bones obres i l'actitud austera dedicada als altres (als quals cal ajudar que trobin el guiatge adequat). Es fonamental no decantar-se, no caure en les temptacions que ofereix a diari el món i, sobretot, desitjar plenament la reconciliació final amb el creador ${ }^{10}$. En aquest sentit, un tema recurrent és el de la justícia divina. Els individus seran destriats en funció de la idoneitat de les seves obres en vida. "Molts seran els cridats, però pocs els escollits" que tindran un destí afortunat per a la seva ànima és una proposició que es reprodueix també en els textos dels Testimonis de Jehovà i del Moviment Hare Krisna ${ }^{11}$. Aquest plantejament respon a la logica d'una divisió estructural de l'existència humana, basada en una

10 -El deseo de instruirse acerca de la ciencia de bhakti-yoga y ocuparse en la Conoiencia de Krisna, es el primer paso en el sendero del perfeccionamiento espiritual. La conciencia de Krisna satisface la más fundamental entre todas las necesidades humanas, que es la de alcanzar el verdadero conocimiento del ser y de Dios; esta es además la condición normal y feliz del ser viviente". Cómo llegar a ser vaisnava, p. 1.

"No es posible para la entidad viviente ser feliz sin prestarle servicio trascendental amoroso al Señor Supremo", BhagavadGita, p. 19.

"...en el mundo material no hay felicidad, pero el agua auténtica de la felicidad existe en el mundo espiritual*. BhagavadGita, p. 21.

"Esta vida es una preparación para la siguiente. Por lo tanto, si podemos prepararnos en esta vida para ser promocionados al reino de Dios, entonces después de dejar este cuerpo material lograremos un cuerpo espiritual igual al del Señor". Bhagavad-Gita, p. 12.

"Quién muere en la luz no retorna a este mundo de dolor; pero el que muere en tínieblas ha de repetir el mortal nacimiento una y otra vez hasta que encuentre la luz*. Bhagavad-Guita. El mensaje del maestro, p. 62.

"Ja és hora de despertar-nos (...) Veniu, fills, escolteu-me, que us ensenyaré el tema del Senyor. Correu mentre tingueu la llum de la vida, perquè no us sorprenguin les tenebres de la mort (...) si volem babitar en el temple d'aquest regne mirem que no s'hi arriba si no és corrent-hi amb les bones obres (...) bem de preparar els nostres cors i els nostres cossos per militar en la santa obediència dels preceptes (...) Amb el progrés en la vida monàstica i en la fe s'eixampla el cor i es corre per la via dels manaments de Déu en la inefable dolcesa de l'amor. Així, no decantant-nos mai del seu mestratge i perseverant en la seva doctrina dins el monestir fins a la mort, participem dels sofriments del Crist amb la paciència, a fi que meresquem de compartir també el Seu regne". Regla de Sant Benet, p.10-13-13/14.

"Si usted ha dedicado su vida sin reserva a Jehová, su meta final es lograr la vida eterna en el justo Nuevo Orden de Jehová (...) Sin aguante no podemos permanecer en la verdad. Si sucumbimos a las presiones mundanas, se nos obliga a volver al mundo (...) Para que sigamos aguantando en estos tiempos dificiles tenemos que cultivar la actitud apropiada hacia el sufrir como cristianos (...) la vida futura es la que está en juego*. Organizados para efectuar nuestro ministerio, p. 116-165165/166).

11 ....entre los millones de hombres de la raza, pocos tienen suficiente discernimiento para desear la perfección y de los pocos que lo desean resultan muy raros los que la alcanzan, pues son contados los que conocen Mi naturaleza esencial*. Bhagavad-Guita. El mensaje del maestro, p. 55.

"Según nuestras actividades en esta vida o nos elevamos o nos bundimos". Bhagavad-Gita, p. 22.

"Los que me adoran son de cuatro clases (...) los desgraciados, los investigadores de la verdad, los vanidosos y los sabios". Bhagavad-Guita. El mensaje del maestro, p. 56. O; "Cuatro clases de hombres piadosos Me rinden servicio devocional: el afligido, el que desea riqueza, el inquisitivo y aquel que busca conocimiento del absoluto". "De éstos, el sabio que está en pleno conocimiento, unido a Mi mediante el servicio devocional puro, es el mejor". Bhagavad-Gita, p. 167.

"Cuantas personas de entre la humanidad serán levantadas para vivir en los cielos con Jesucristo?. (...) ciento cuarenta y cuatro mil que tienen eserito en sus frentes el nombre de El y el nombre de Su padre (...) ciento cuarenta y cuatro mil que han sido comprados de la tierra". (Rev.14:1,3). Es menciona tot seguit que all jutjaran i seran sacerdots de Déu i de Crist; la resta, seran jutjats individualment segons els fets. Organizados para efectuar nuestro ministerio, p. 188 (Apèndix). 
oposició binària de valors: virtut-maldat, justícia-injustícia $\mathrm{i}$ veritat-falsedat principalment ${ }^{12} \mathrm{i}$ descansa en la idea general que presenta els dies d'aquesta vida com a una treva que la divinitat concedeix l'home a fi que esmeni les seves maleses.

Com a condicions prèvies fonamentals a l'acceptació i posterior iniciació en el grup religiós s'exigeix renúncia explícita a la voluntat pròpia i lliurament total al servei de Déu en el marc de la comunitat. El compromís ferm i l'obediència són predisposicions essencials. Més endavant s'insisteix en la resistència a les temptacions de la ment i els sentits; el procés reformador implica un sacrifici amb un referent diví que el justifica $i$ impulsa, $i$, en conseqüència, rebrà la seva sublim recompensa futura. En la mateixa línia, és important també la renúncia voluntària a béns materials personals ${ }^{13}$.

L'aspirant, ja sigui l'estudiant cèlibe Hare Krisna, el novici benedictí o l'estudiant de la Bíblia Testimoni de Jehovà, té un seguiment estret per part de persones considerades avançades en sentit espiritual, les quals comprovaran la idoneitat del candidat fins al moment de la iniciació $\mathrm{i}$ donaran conformitat a la corresponent adquisició per part de l'individu d'un nou estatus a la comunitat. El procés iniciàtic consistirà a educar $\mathrm{i}$ entrenar el futur membre en una nova forma de vida $i$ de pensament, tot amotllant paulatinament la seva escala de valors i conducta quotidiana a la normativa de l'organització i a les obligacions que se'n deriven. Haurà d'habituar-se des d'un principi a la regulació del col-lectiu, rebrà ajuda i consell en el seu desenvolupament moral, i caldrà que vagi demostrant les seves aptituds amb paraules i fets. El progrés espiritual i el coneixement doctrinal esdevindran un indicatiu fonamental en l'adquisició de prestigi a la comunitat. La relació amb persones més avançades sempre serà de profit en aquest sentit; el nèfit podrà acudir-hi en

\footnotetext{
12 -Aquellos que son envidiosos o malévolos, los cuales son los más bajos entre los hombres, Yo los arrojo en el océano de la existencia material dentro de varias especies demoniacas de vida. Hay tres puertas que conducen al infierno: la lujuria, la ira y la codicia (...) El hombre que se libra de estas tres puertas ejecuta actos conducentes a la autorrealización y así alcanza gradualmente el destino supremo (...) Pero aquel que hace a un lado los mandamientos de las escrituras y actua de acuerdo con sus propios caprichos, no alcanza ni la perfección ni la felicidad, ni el destino supremo". Bhagavad-Gita, p. 330 a 335 .

"A estos impíos, malvados y aborrecedores que me odian y odian todo lo bueno, Yo los arrojo en demoníacas matrices para que contínuamente renazcan en planos inferiores. Y caidos en profundos abismos, si alucinándose de nacimiento en nacimiento no aprenden las lecciones de la experiencia ni les llega a repugnar el cieno de la sensualidad, y prefieren irse hundiendo en planos cada vez más bajos, al fin serán aniquilados*. Bhagavad-Gita, p. 114.
}

"Se ha dado un tremendo testimonio que ha resultado en dividir a la gente (...) Jesucristo, junto con sus santos ángeles, ha estado efectuando una separación entre los que aman la justicia y los que son indiferentes a la verdad o que se oponen activamente a ella". Organizados para efectuar nuestro ministerio, p. 7-8.

13 "El vaisnava posee todas las cualidades de un brahamana (ser humano de primer orden) y está siempre ocupado en el servicio puro de devoción a Dios (Krisna) (...) El deseo de unirse a la Asociación Internacional para la Concieacia de Krisna y de ser iniciado por un maestro espiritual auténtico, demuestra el anhelo del estudiante de someterse voluntariamente al proceso reformador del Bhakti-yoga". Cómo llegar a ser vaisnava, p .2.

\footnotetext{
"A tu, doncs, s'adreça la meva paraula, siguis qui siguis que renunciant als teus propis volers per militar per el senyor Crist, el rei veritable, prens les fortissimes i esplèndides armes de l'obediència". "Si poseeix bens, o que abans els distribuieixi als pobres o que amb una donació legal els cedeixi al monestir, sense reservar-se res de res*. Regla de Sant Benet, p. 9-22.

"Vale la pena todo sacrificio que tengamos que hacer solo para ser llamados por el nombre de Jehová". "los testigos de Jehová (...) también consideran un privilegio el utilizar su dinero y otras posesiones materiales para dar adelanto al ministerio cristiano". "Como cristianos dedicados, reconocemos que nuestro tiempo, haberes mentales y físicos, talentos, posesiones materiales y hasta nuestra misma vida, son dádivas procedentes de Dios y se nos han dado para que las usemos en su servicio". Organizados para efectuar nuestro ministerio, p. 137-120/121-126.
} 
qualsevol moment i per qualsevol qüestió que l'afecti ${ }^{14}$.

Les pautes ideolうgiques i comportamentals dins l'àmbit comunitari parteixen de dues premisses bàsiques: amor i devoció permanent a la divinitat i seguiment dels preceptes de les escriptures sagrades ${ }^{15}$. A partir d'aquí, és imprescindible una conducta ajustada a la normativa legal de l'organització amb potenciació de les bones qualitats (misericordia, humilitat, imparcialitat, hospitalitat, respecte, tolerància, lleialtat, benignitat, serietat, etc.) i subjugació de les dolentes (inherents a la condició humana). Així, s'insistirà en tota una sèrie d'actituds: evitar la mundanalitat i els plaers que se'n deriven; no implicar-se en aspectes polítics ni socials en general; no atribuir els fets positius al propi enginy o habilitat sinó a la "mà suprema" i els negatius acceptar-los amb resignació ja que són senyal de càstig diví per les males accions personals (presents o passades); tenir consciència de l'omnipotència i omnipresència de Déu; mostrar obediència i submissió a l'autoritat de la comunitat i dirigir-s'hi per qualsevol afer personal o espiritual; manifestar austeritat, desprendiment i moderació emotiva; concentrar-se en el vessant espiritual i estudiar els textos sagrats expressant amb fets les seves ensenyances; venerar els avançats de la comunitat tot cercant el seu consell, i, en suma, procurar el benestar comunitari en el marc de la convivència harmònica amb la resta de fidels.

S'observa que la iniciativa individual es restringeix a tots els nivells i es passa a estimular una fraternitat comunitària fonamentada en un consistent sistema d'autoritat. Si limitant al màxim la voluntat pròpia del fidel, s'evita la seva tendència a satisfer els desitjos que li creen els sentits, per l'altre cantó, l'associació fraternal s'aconsegueix mitjançant l'eliminació de la propietat privada (res pertany a ningú ja que tot és de Déu) i l'exigència d'un respectuós tracte mutu sota la subordinació plena al superior espiritual, el personatge cohesionador per excel-lència. Així mateix, evitar la relació amb persones reaccionàriament alienes al grup o de mentalitat dissident dins d'aquest és molt important; els "vents de mundanalitat" que porten bufen a favor de l'heterogeneitat

14 -El aspirante debe poner gran cuidado en desarrollar una actitud de sumisión, indagación y servicio hacia el maestro espiritual. Debe entregarse en cuerpo y alma a la instrucción del guru, cumplir estrictamente los cuatro principios regulativos (no comer carne, pescado, ni huevos; no realizar actos sexuales ilícitos; no tomar intoxicantes; no jugar juegos de azar) y cantar diariamente en su rosario de 108 cuentas el mantra Hare Krisna, dándole dieciseis vueltas. Además en las plegarias Gurvastaka se asevera el prosternarse a los pies de loto de su maestro espiritual, al menos tres veces al dia. Cuando el guru está físicamente presente, debe postrarse ante él cada vez que lo ve ${ }^{*}$. Cómo llegar a ser vaisnava, p. 7-8.

"Quan algú es presenta per primera vegada per fer-se monjo, que no l'admetin facilment (...) Si després de quatre o cinc dies, es veia que suporta amb paciència els greuges que ti han fet i la dificultat de l'admissió i que persisteix en b seva demanda, que li concedeixin l'entrada i que s'estigui uns quants dies a l'hostatgeria. Després entrarà al noviciat, on ha d'estudiar, menjar i dormir. Que se'ls destini un ancià que sigui capaç de guanyar les ànimes, el qual ha de vetllar damunt d'elles molt atentament". Regla de Sant Benet, p. 120.

"Una cooperación estrecha entre los ancianos y el que conduce el estudio biblico ayudará al nuevo a llegar a ser un điscípulo genuino. A medida que el estudiante de la Biblia progresa, amoldará su modo de vivir a las normas justas de Jehová y, según sus circunstancias personales, asistirá con regularidad a las reuniones de la congregación y empezará a participar actiramente en el servicio del campo. La persona que de esta manera esté demostrando que realmente desea llegar a ser testigo de Jehová puede abordar a uno de los ancianos y expresar su deseo de bautizarse. (...) Los ancianos se asegurarán de que la persona a quien se bautiza baya adquirido un entendimiento razonable de las enseñanzas biblicas fundamentales (...) darán consideración a los antecedentes, la aptitud y otras circunstancias de cada persona que desea bautizarse". Organizados para efectuar nuestro ministerio, p. 174-175.

15 ....tenemos que practicar el recordar siempre al Señor veinticuatro horas al día, cantando Sus santos nombres y amoldando las actividades de nuestra vida de tal manera que podamos recordarlo en todo momento*. Bhagavad-Gita, p.23.

"Abans de tot, estimar el Senyor Déu amb tot el cor, amb tota l'ànima, amb totes les forces". Regla de Sant Benet, p.24.

"Tienes que amar a Jehová tu Dios con todo tu corazón y con toda tu alma y con toda tu mente y con todas tus fuerzas". Organizados para efectuar nuestro ministerio, p. 111. 
i l'especulació dins la comunitat, contraris al sentiment homogeni i solidari que ha de predominar en tot moment ${ }^{16}$.

En relació amb l'aspecte sociabilitat i comunicació amb l'exterior, la Regla de Sant Benet és bastant estricta amb els monjos en quant a permissibilitat d'abandonament de la institució. Tot i aixd, difícilment es tanquen de forma definitiva les portes a aquell que una vegada fora vol retornar; només s'exigeix que estigui disposat a rectificar plenament la conducta que el portà a sortir ${ }^{17}$. Quelcom semblant succeeix en el cas dels Hare Krisna. En aquest col-lectiu, en principi, no es parla de cap obstacle especial a la sortida del grup; si un individu no té el suficient convenciment devocional i li resulta impossible suportar el dur programa espiritual de la comunitat, pot marxar sense problemes si aixf ho desitja. Altrament, si es penedeix de la seva decisió $\mathrm{i}$ vol tornar, l'autoritat interna considerarà el tema però rarament hi posarà cap impediment, sempre i que la persona accepti determinades condicions per a la seva reintegració i faci totalment efectiu el compliment de la normativa institucional. En cas que n'hagi estat expulsat, la revisió de la

${ }^{16}$ Dos plantejaments primordials de la filosofia Hare Krisna són prou significatius pel que fa al valor atribuit a l'individu com a tal $\mathrm{i}$ a les seves accions: el cos humà ("cuerpo burdo") no és més que l'embolcall transitori de l'ànima, i Krisna o el Suprem és el creador i el gaudidor de tot allo creat; les persones estan destinades a cooperar amb Ell per satisferlo, subjugant els propis desitjos: "El que cumple la recta acción y no apetece su fruto, renuncia a la acción. De esta suerte, es capaz de domeñar sus sentidos y reprimir sus deseos, de trascender la personalidad y adquirir el conocimiento de su verdadero Yo, esencialmente uno con el Yo de todos los seres (...) El hombre ansioso por el fruto de sus acciones, no halla la paz, porque lo conturba el deseo de remuneración. Libre el sabio de las acciones y de sus resultados, mora en el Templo del Espíritu, al que los hombres llaman cuerpo, y permanece en tranquila paz, sin deseo de acción ni de su causa de acción, pero dispuesto a desempeñar su parte en la acción cuando lo exijan los deberes de su estado. Porque sabe que aunque su cuerpo, sentido y mente puedan empeñarse en la acción, su verdadero ser permanece siempre imperturbado" (BhagavadGuita. El mensaje del maestro, p. 42-43). "Los sentidos, asesorados por la mente, ofrecen sensaciones de calor y de frío, de placer $\mathrm{y}$ de dolor; pero estas son cosas transitorias y mudables. Sopórtalas valerosamente porque en verdad te digo que al hombre a quien estas cosas no contaban, que permanece incólume al placer $y$ al dolor, $y$ para quien todo es igual, está en el camino de la inmortalidad". Bhagavad-Guita. El mensaje del maestro, p. 21.

D'altra banda, malgrat que a la pràctica hi hagi molta més flexibilitat, la normativa diu: "Debemos asociarnos únicamente con personas que han desarrollado la Conciencia de Krisna (...) la compañía incluso de un vaisnava debe evitarse si este no tiene buen caràcter (...) también deben evitarse (...) conversaciones mundanas acerca de temas mundanos, porque pueden llegar a destruir nuestro servicio devocional". Como llegar a ser vaisnava, p. 13.

"Tota exaltació de si mateix 6 s una forma d'orgull (...) la voluntat pròpia se'ns prohibeix de fer-la, en dir-nos l'escriptura: "Aparta't dels teus volers" (...) No estimant la seva voluntat, l'home no es complau a satisfer els seus desitjos (...) guardantse tothora de pecats i de vicis, això és, dels pensaments, de la llengua, de les mans, dels peus i de la voluntat pròpia, com també els desigs de la carn, 1 'home ha de comptar que Déu l'observa tothora des del cel $\mathrm{i}$ que en tot lloc les seves accions són presents a la mirada de la divinitat". Regla de Sant Benet, p. 34-36-37-35. "Además de evitar envolvernos con el mundo en sus campos de la política y lo social, tenemos que resistir el degradante
ambiente moral del mundo (...) Aunque las atracciones mundanas ejercen vigorosa influencia, no debemos siquiera empezar
a desear lo que el mundo ofrece. (...) tenemos que negarnos a permitir que nuestra mente se espacie en cosas que son
obscenas, vergonzosas o bajas, y no debemos considerar tales cosas en conversación innecesaria. Tenemos que evitar que
se ejerza influencia inmoral en nosotros por estar observando al gún despliegue público de inmundicia o suciedad como forma
de entretenimiento. (...) Este tiempo no es tiempo apropiado para pensamiento independiente (...) Jesús no hizo ni una sola
cosa de su propia iniciativa; no habló de su propia originalidad ni buscó su propia gloria". Organizados para fectuar nuestro
ministerio, p.129-8-13.

17 "(...) I si després d'haver-s'hi pensat, prometia de complir totes les coses i d'observar tot el que li manin, llavors sigui admès en la comunitat; però ha de saber que la llei de la Regla estableix que a partir d'aquell dia no li serà lícit d'anarse'n del monestir ni sostreure el coll de jou de la Regla, que després d'haver-s'ho pensat tant pogue refusar o acceptar". Regla de Sant Benet, p. 121.

"Si un germà que per culpa pròpia surt del monestir volia tornar, ha de prometre la total esmena d'allo per què va sortir $i$ aleshores que l'admetin al darrer lloc, per comprovar amb aixo la seva humilitat. I si se'n tornava a anar, que l'admetin semblantment fins a tres vegades; però sàpiga que en endavant li serà negada tota possibilitat de retorn". Regla de Sant Benet, p. 72. 
qüestió serà més profunda i les condicions, més estrictes. Quant als Testimonis de Jehovà, la disposició normativa és bastant més radical: dissociació és sinònim de marginació absoluta i expulsió pràcticament definitiva del cós de fidels ${ }^{18}$.

Pel que fa als processos d'acolliment d'individus interessats (en definitiva potencials futurs membres), la postura regulativa més comuna és la de no posar-hi límits sinó més aviat el contrari. Es considera positiu que altres persones s'acostin a la comunitat per gaudir de l'ambient de fraternitat i espiritualitat que allí es respira. Per aquest motiu, tant per als Testimonis de Jehovà com per als Hare Krisna el fet de donar a conèixer el camf correcte i la paraula de veritat a través de la prèdica és sempre una tasca no sols gratificant, sinó també necessària per al desenvolupament i regeneració del moviment. Ara bé, "proveu els esperits si són de Déu" abans d'acceptar-los diu la Regla benedictina. El pas cap a la conversió, d'acord amb les elevades finalitats d'aquesta, requereix en tots els casos una observació estreta i detinguda de la persona que la desitja.

Dins la communitas normativa, com ja s'ha apuntat amb anterioritat, l'ordenació estamentària del col-lectiu s'efectua en base a les qualitats de vída i a l'avanç espiritual en general, que inclou un ampli coneixement i raonament de la doctrina sagrada. En relació amb això, es considera del tot imprescindible la subordinació-subjecció a les persones dotades d'experiència, que saben quines poden ser les possibles "caigudes" dels nedfits i els seus motius, així com el remei adequat a cadascuna ${ }^{19}$.

Sobre aquestes bases institucionals relatives a l'articulació i expressió de l'experiència religiosa, entrem a continuació en el terreny de les prescripcions quotidianes més immediates. Així, a nivell expositiu distingirem entre: les relatives al comportament formatiu i recreatiu, les de caràcter físic $\mathrm{i}$ higiènic, les de tipus sexual $\mathrm{i}$ les referents a alimentació $\mathrm{i}$ consum d'intoxicants. D'altra banda, l'actitud idònia en els processos d'expressió simbòlico-ritual i els mecanismes de sanció per la transgressió de la normativa interna, ocuparan la part final d'aquest article.

La lectura i estudi dels textos sagrats i, en especial, de la normativa que aquí es tracta, es considera fonamental. Els fidels han d'ocupar unes hores determinades en aquesta tasca si volen créixer en espiritualitat. L'aprehensió dels significats i continguts d'adoracions, ofrenes i pregària amb l'objecte de posar la pròpia vida en conformitat amb l'ensenyança sagrada $i$ aplicar-hi els seus exemples, enforteix contra la mundanalitat i la conducta equivocada o pecaminosa. Més que cap altre, l'estudiant novici ha de concentrar tota la seva atenció en els documents inspirats per la divinitat, de manera que gradualment sigui capaç d'emetre un discurs en harmonia amb aquests i mai "según sus propias ideas o falsas enseñanzas religiosas" (1983:98).

En els grups on es permesa l'estructura familiar (Hare Krisna i Testimonis de Jehovà) un

18 - Al que se ha disociado por haber repudiado la fe y deliberadamente haber abandonado la adoración de Jebova se le considera del mismo modo que a una persona que ha sido expulsada*. Organizados para efectuar nuestro ministerio, p. 151.

19 -Del mismo modo que no se puede prescindir del guru para aproximarse a Krisna tampoco se puede prescindir de los demás vaisnavas para aproximarse directamente al maestro espiritual. En la vida devocional uno debe primero transformarse en un sirviente del sirviente del Sed̃or (...) La causa original del servicio de devoción a Sri Krisan es la asociación con devotos avanzados*. Cómo llegar a ser vaisnava, p. 8-9.

"El qui hagi arribat al monestir a l'hora segona, consideri que és més jove que aquell que ha arribat a la primera bora del dia, de qualsevol edat i dignitat que sigui. A qualsevol banda que es trobin els germans, el més jove demanarà la besedicció al més gran". Regla de Sant Benet, p. 132.

"A toda persona se da entendimiento de la interdependencia que existe entre todos. Cada persona que sirve en la congregación trabaja para el tren común de todos y en esparcir las buenas nuevas del reino (...) nos beneficiamos mís aún si continuamos sometiéndonos a los ancianos de la congregación y a otros superintendentes nombrados a quienes se ha encargado el pastoreo del rebaño y la superintendencia de la obra*. Organizados para efectuar nuestro ministerio, p. 54. 
element important a tenir en compte és el de la socialització religiosa dels fills. Amb vistes a la reproducció del grup, es recalca sempre la necessitat d'una certa vigilància i la conservació de la disciplina vers els infants; en aquesta direcció, durant la seva formació educativa s'insisteix en donar preeminència als aspectes espirituals i en distanciar de l'experiència mundana o informal. Es tracta, en suma, d'impulsar primàriament la prole cap a una consciència formada en harmonia amb els plantejaments del col-lectiu religiós al que es pertany, en una mostra de subordinació fidel i de lliurament d'aquells que poden ser els seus efectius continuadors.

En relació amb el descans i temps d'esbarjo, en línies generals es recomana no dormir més del necessari; en tots els casos, l'ociositat és enemiga potencial de l'ànima. En les formes de vida "retirada", ja sigui benedictina o Hare Krisna, la regla és bastant rigorosa en aquest sentit, de manera que els avançats espiritualment han de vetllar amb força pel compliment de l'horari establert a la comunitat per part dels neofits ${ }^{x 0}$. Així, el temps de lleure es destina gairebé de forma exclusiva a la lectura i a les ocupacions de caràcter espiritual. Aquesta concentració místicadevocional evita caure en entreteniments entesos com a desmoralitzadors i en nocives especulacions mentals que entren entre dins la logica del temps perdut o de la intranscendència existencial.

Tocant als aspectes físics relatius $\mathrm{a}$ indumentària bàsicament $\mathrm{i}$ als de caràcter higiènic, val a dir que en els dos casos de vida monàstica la vestimenta és senzilla $\mathrm{i}$ adequada en forma $\mathrm{i}$ mida a les característiques d'austeritat predominants. En general, a les tres instàncies religioses que s'analitzen és posa l'accent en l'aparença modesta, que ha de millorar ostensiblement quan el fidel surt de la comunitat $\mathrm{i}$ es relaciona socialment ${ }^{21}$. Cal fomentar una bona opinió pública, en el sentit de què es vegi en l'endreç extern el reflex de la puresa espiritual.

Neteja física (exterior) i neteja espiritual (interior) són condicions que van aparellades. La primera simbolitza purificació; el contacte amb el cos impur contamina, per tant, el constant procés purificador és imprescindible. La segona és senyal de santedat i la forma correcta d'apropar-se a la divinitat, que no ha de veure res indecent en el fidel.

Apropem-nos ara, d'una banda, al tema de la sexualitat, i d'una altra, al del consum d'aliments i productes tòxics.

En la logica de la impuresa del $\cos$ i del rebuig dels desitjos derivats dels sentits imperfectes, és comuna una considerable restricció sexual de pensament i obra. Les relacions sexuals es prohibeixen sistemàticament o queden circumscrites al marc formal del matrimoni $\mathrm{i}$ la

20 "No se debe dormir mas de seis o siete horas al dia i no debe uno levantarse después de las cuatro de la madrugada*. Como llegar a ser vaisnava, p. 35.

•Els germans més joves, que no tinguin els llits de costat, sinó entre mig dels ancians (...) A I'hivern (...) es llevaran a I'hora vuitena de la nit, calculada raonablement, de manera que no dormin una mica més de la meitat de la nit, i s'aixequin ben reposats (...) des de Pasqua fins al susdit primer de novembre, que es reguli I'hora de tal manera que a la celebracio de les vigilies (...) segueixin inmediatament les laudes que s'han de celebrar a trenc de l'alba*. Regia de Sant Benet, p. 42.

21 "Cuando el devoto se viste, especialmente para ir a lugares públicos, debe tener presente el hecho de que está representando a Krisna, a su maestro espiritual y a toda la comunidad vaisnava. Por lo tanto su apariencia debe ser impecable (...) toda su apariencia debe causar una buena impresión a quien quiera que lo vea*. Cómo llegar a ser vaisnava, p. 35.

"...que hi hagi també cogulles i túniques una mica millors que les que solen portar en sortir de viatge". Regla de Sant Benet, p. 116.

"Nuestro arreglo personal y modo de vestir deben estar en armonia con los principios piadosos (...) Nuestro arreglo personal y los estilos de nuestro vestir pueden ejercer influescia en otros y afectar el modo como ven la verdadera adoración de Jehová (...) cuando participamos en el ministerio del campo o nos congregamos para la adoración en las reuniones de la adoración, asambleas de circuito o asambleas mayores, debemos tener presente lo que las Escrituras dicen acerca de la limpieza física y la apariencia modesta, para que siempre honremos a Jehova". Organizados para efectuar nuestro ministerio, p. 130-131. 
famnlia i a la finalitat procreadora (Hare Krisna i Testimonis de Jehovà). "Subjugar els desitjos de la carn", "estimar la castedat" i "no lliurar-se als plaers", són deures especificats per la normativa benedictina que poden fer-se extensibles als paràmetres ideologics de les altres dues estructures institucionals objecte de comparació.

El sistema de pensament vèdic, origen i guia filosòfico-pràctica del Moviment Hare Krisna, ensenya l'home com evitar la vida sexual per poder progressar gradualment a nivell espiritual d'una manera prou explícita: "la mujer es como el fuego y el hombre como la mantequilla. Si la mantequilla la acercas al fuego se derrite" (H., 22-X-92 $)^{22}$. Hi ha una instrucció central: el tracte entre els dos sexes ha de reduir-se al mínim compatible amb el bon servei a Krisna. Així, és essencial limitar l'expressivitat femenina, considerada perillosament provocativa i per tant desviadora de la normalitzada condició humana de devoció, i confinar la dona als rols típics de la feminitat tradicional, els que li corresponen "per naturalesa". Pel sexe femenf s'emfasitzen fonamentalment els valors de maternitat, puresa, castedat i servei incondicional al marit. Quelcom semblant succeeix amb el programa ideològico-religiós dels Testimonis de Jehovà; per ells, seguint la jerarquia d'autoritat marcada pel principi teocràtic, la dona té un paper secundari, és l'ajudant o complement de l'home, el cap de familia ${ }^{23}$.

Podem parlar doncs, per un cantó, d'una exigència de viure en harmonia amb les ensenyances sagrades respecte al pecat que representen les activitats sexuals il-lícites, tals com les relacions extramatrimonials, l'homosexualitat, l'adulteri, etc., i entre les quals també s'inclouen el fet de pensar-hi i parlar-ne, i, per un altre, d'una forta segregació de rols sexuals en els grups religiosos on, segons principis sacramentals propis, és permesa l'aliança matrimonial.

Sobre el comportament alimentari, cal assenyalar el predomini de la línia general d'austeritat que ha de caracteritzar tota actitud espiritualista, inclosos períodes concrets de dejuni durant l'any. No ha d'existir ni l'abús ni el menyspreu d'aliments ja que són donació divina i, per tant, tenen una connotació sagrada. L'evitació específica de la carn és un element normatiu essencial entre els Hare Krisna i que també apareixia originalment a la Regla Benedictina, malgrat no seguir-se en l'actualitat ${ }^{24}$. Existeix també un control o prohibició explícita (Hare Krisna) del consum d'intoxicants i productes estimulants en general, que contaminen el cos i la ment. El rigor normatiu en aquest aspecte variarà segons les bases doctrinals de cada àmbit religiós, però en qualsevol cas l'abstenció es considerarà una virtut concedida per Déu que serà convenientment recompensada ${ }^{25}$.

22 El sexe es cosidera la temptació que més costa de superar. Així, l'informant esmentat afegeix: "en los Vedas sale el impulso sexual y de hecho es la trampa por la cual las almas están atrapadas en el mundo material. Es la trampa, es el placer más grande que existe*.

23 "Dentro de la estructura del matrimonio y la familia, a los esposos se les asigna la posición de jefatura, puesto que "la cabeza de la mujer es el varón" (...) Las esposas ban de estar en sujeción a sus esposos, y los hijos a sus padres. Cuando cada familia sigue el principio de la jefatura, el resultado es fruto apacible (...) El papel de la esposa es el de una ayudante o complemento*. Organizados para efectuar nuestro ministerio, p. 14-15.

24 "...tots $\mathbf{s}$ 'han d'abstenir absolutament de menjar carn de quadrúpedes, llevat dels malalts molt debils". Regla de Sant Benet, p. 88.

"El que come carne embota sus sentidos, olvidando a Dios, y siendo condenados, una vez muertos a reencarnarse en animales". (Cfr. Pozuelo, F., 1990:150)

Aquest plantejament s'emmarca en el context d'un dels quatre principis regulatius del Moviment Hare Krisna: no menjar carn, peix ni ous. Es considera que tot animal té una ànima espiritual; per tant, matant-lo es comet un gravíssim pecat que tindrà el seu càstig en vides posteriors.

25 -Además de la carne, el pescado y los huevos, otras sustancias impuras son las cebollas, el ajo, los hongos, el queso elaborado con cuajo animal, la gelatina y sus derivados y el chocolate; ninguna de las cuales debe ser ofrecida al señor. Entre los intoxicantes -prohibidos, por cierto-se incluye el café, el té, el tabaco, las nueces de betel, y varias especies que se usan 
D'altra banda, pel que fa a l'expressió simbolica i ritual, observem en especial una forta coincidència entre els oficis divins benedictins i les adoracions Hare Krisna. En ambdós casos, s'estructuren al voltant d'un horari sequiencialment pautat que s'inicia abans de la sortida del sol, reben una denominació concreta i distintiva respecte a altres activitats comunitàries, i fins i tot es duen a terme igual nombre de vegades al dia. Els monjos de l'Orde Benedictí tenen els segūents moments d'oficis i pregària: laudes, prima, tèrcia, sexta, nona, vespres i completa; els devots Hare Krisna: Mangala arati, Tulasi puja, Guru puja, Raja Bhoga arati, Dhupa arati, Sandhya arati i Sayanna arati. Així mateix, pot establir-se un clar paral-lelisme entre el rés del rosari benedictí i el cant del japa o recitació del Maha-mantra Hare Krisna, també amb un rosari de comptes.

Tot i que obviament la logica formal de la litúrgia i oració varia en funció del sistema específic de creences, l'actitud religiosa imprescindible és la mateixa: ha de fer-se en plena consciència de la divinitat $\mathrm{i}$ de la seva omnipotència/omnipresència, amb humilitat $\mathrm{i}$ reverència, molt devocionalment i en total concentració espiritual. Una profunda veneració i respecte mereixen també documents i objectes sagrats, siguin emprats o no en el culte; les escriptures, en tant que constitueixen el fonament interior de l'espiritualitat, i els objectes, en tant que permeten exterioritzar-la aquesta espiritualitat i reprojectar-la novament a la divinitat que la fa possible.

A l'interior de la comunitat, $\mathrm{i}$ amb la intenció de vetllar pel recte compliment de la normativa, existeixen diferents mecanismes de control o castig. La imperfecció humana provoca que sovint es caigui en actituds equivocades, però a partir d'aquí allo correcte és acceptar la censura i cercar el perdó. La sanció s'aplicarà en relació a la falta comesa, i només si la gravetat de la situació ho requereix s'expulsarà l'infractor com a mesura de protecció de la resta de fidels $^{26}$. Com ja s'ha dit més amunt, és necessari que qualsevol element perturbador sigui separat temporal o definitivament de la comunitat a fi i efecte que no influencii negativament la resta de membres. En qualsevol cas, val a dir que reconèixer en propietat la falta comesa $\mathrm{i}$ intentar esmenarla minimitza la represàlia. El penediment en paraula i obra permetrà el restabliment progressiu de l'individu a la comunitat, tot i que la seva acceptació impliqui un seguiment estret per comprovar que realment ha decidit reincorporar-s'hi sota la norma justa.

Les qũestions molt personals o de difícil solució seran comunicades només a l'autoritat de la comunitat o als mestres espirituals, que evitaran que es facin públiques i puguin alarmar inconvenientment la comunitat, tot distorsionant la seva estabilitat. Cal deixar el problema en mans dels responsables $\mathrm{i}$ confiar en la misericordia divina, ja que, en definitiva, la disciplina $\mathrm{i}$ censura de qualsevol activitat humana no és més que l'expressió de l'amor diví vers l'home.

Fins aquí l'exposició comparada de la trilogia canònica escollida. Ara bé, no voldríem acabar aquest apartat sense abans afegir una puntualització important: una cosa és la "teoria"

para preparar el pan". Como llegar a ser vaisnava, p. 35.

•...creiem que és suficient per a cadascú una hèmina de vi al dia. Aquells, tanmateix, a qui Déu dóna de poder-se'n estar, sàpiguen que tindràn una recompensa especial". Regla de Sant Benet, p. 89.

"¿Obedece el estudiante la prohibición biblica en cuanto a la borrachera?, ¿Se mantiene limpio de la contaminación del tabaco, la areca y otras cosas que contaminan el cuerpo?, ¿Se abstiene del uso sin propósitos médicos de drogas que crean adicción?". Organizados para efectuar nuestro ministerio, p. 98.

${ }^{26}$ Comentari d'un informant Hare Krisna: "Si en la caja bay una manzana podrida es mejor sacarla para proteger al resto de las manzanas". (H., 5-XI-92).

"...i si ni d'aquesta manera no es guaria, aleshores que l'abat faci ús ja del ferro de l'amputació (...) no fos cas que una ovella malalta contagiés tot el ramat". Regla de Sant Benet, p. 70-71.

"...quizá sea necesario que los superintendentes expulsen al malhechor que no se arrepiente y de ese modo proteger al rebaño y salvaguardar la limpieza de la congregación. Organizados para efectuar nuestro ministerio, p. 145. 
preceptual i una altra la "pràctica" diària. El referent regulatiu ha d'estar sempre present a l'imaginari d'aquells que l'han acceptat, donada la fermesa argumental i orientativa que el caracteritza. Però arran de l'evolució sòcio-històrica global i de les transformacions internes de les mateixes institucions religioses, molts aspectes de la quotidianeitat a l'interior d'aquestes institucions no s'ajusten al peu de la lletra als postulats marcats pel text normatiu. Aixo és especialment patent en allo relatiu a criteris conductuals de tipus físic, alimentari i, en general, d'encapsulament $\mathrm{i}$ austeritat vivencial a diferents nivells ${ }^{27}$. Per aquest motiu, al meu entendre, qualsevol aproximació rigorosa al tema que aquí s'ha volgut presentar, ha de passar pel filtre d'una revisió dels informes que el dossier (vol. 8) inclou per a cada grup religiós en particular i, en especial, del seu capítol dedicat a forma de vida.

\section{A manera de conclusions}

Reprenent els plantejaments temàtics que encetaven aquest article i tot el que s'infereix de les pàgines anteriors, algunes breus consideracions finals podrien ser aquestes:

1/ Regularment, els diferents codis culturals tendeixen a ser estructurats per part dels grups de poder i control que representen l'ideal social sota uns paràmetres normatius molt concrets i bastant recurrents en la forma $i$ en el fons. Per molt espars que siguin d'arrel original i llurs projeccions simboliques i socials, aquests codis són ordenats subjectivament per configurar i activar mecanismes regulatius institucionals des de l'interior dels sistemes socials en general (a partir de l'organització político-civil dominant) i dels sistemes de fe en particular (a partir de l'organització religiosa hegemònica). Uns mecanismes que, en definitiva, estarien orgànicament constituïts per neutralitzar o minimitzar el "perill místic" que representen les situacions liminals o els rols no incorporats ritualment segons la tradició al context liminal. Aix́, segons Turner (1988:115): "desde la perspectiva de quienes se interesan por el mantenimiento de la "estructura", todas las manifestaciones prolongadas de communitas deben parecer peligrosas y anárquicas, por lo que deben ser acotadas por medio de prescripciones, prohibiciones y condiciones". Una vegada formalitzades $\mathrm{i}$ instituïdes tals limitacions, l'efectivitat d'aquestes anirà lligada a la seva capacitat per a sistematitzar, articular i mediatitzar els sentiments i els estats emotius més diversos, entre ells, en la forma que aquí ens ha ocupat, aquells caracteritzats per una aspiració específica: l'espiritual o contemplativa.

2/ Dos factors d'especial centralitat en la dinamització dels organigrames socials haurien de considerar-se en l'anàlisi més precisa de la temàtica que s'ha desenvolupat. Ens referim a l'organització del poder $\mathrm{i}$ als vincles (metaforics) de parentiu. El primer, pels seus dispositius simbòlics d'execució del control social, habitualment fonamentats en un model jeràrquic d'autoritat/supervisió ben definit i bastant rígid; els segons, a dos nivells: d'una banda, en el seu paper socialitzador i de formació d'identitats (en aquest cas religioses) ${ }^{28}$, i d'una altra, en tant que potenciadors d'estretes relacions de solidaritat en termes indissolubles o de llarga durada (la

27 En el sentit d'asincronia temporal serveixi d'exemple més clar la Regla de Sant Benet, redactada al segle VI.

28 Sembla que en la majoria dels casos aquests processos se centrarien entorn d'un fenomen d'autodescobriment personal davant el "mirall fix" de la disposicio institucional. Les diferents fases i vicissituds iniciàtiques de l'experiència religiosa, per la seva banda, aparentment estarien en relació amb el joc d'encaix entre l'impuls motivacional individal $i$ els models simbolico-representatius d'identificació projectats per la institució. Del grau d'ajust d'aquesta connexió dependrà, en última instància, la integració definitiva en el sistema de fe i la progressiva conscienciacio i construcció identitìria del fidel al seu interior. 
comunitat normativa com a imatge de la institució familiar) sota una aureola motivacional i finalista comuna.

3/ Es prou conegut que la vida contemplativa exigeix a aquells que l'han escollit, a més d'uns cànons organitzatius "exteriors", l'autoimposició d'una rigorosa disciplina (regulativa) interna, que vindria a sintetitzar-sublimar a nivell d'experiència el conjunt d'actituds $i$ hàbits requerits en coherència amb el sistema religiós del qual es participa. Es en aquest sentit que podríem parlar d'una constant retroalimentació normativa individu-institució. La religió proporciona les bases mítiques-doctrinals i ideologiques que impregnen de significat simbòlic l'organització i normativa institucional, i aquesta, al seu torn, ofereix al fidel les directrius d'orientació (amb els seus corresponents marges de flexio) a partir de les quals la síntesi cognitiva-identitària prèviament interioritzada ha d'exterioritzar-se de forma adequada i sense desviacions, és a dir, focalitzant-se envers àmbits conductuals que no depassin els marges tolerats.

La presència permanent a la consciència individual i col-lectiva d'una cosmovisió específica on tots els fets s'expliquen des de la seva totalitat, i d'una ordenació pautada de la quotidianeitat partint de la regla, es traduiria en el que podríem dir una "simbiosi automàtica" pensament/acció personal-quadrant normatiu institucional ${ }^{29}$. Simbiosi que, d'altra banda, quedaria actualitzada $i$ revisada de forma regular a ritme de processos d'integració-sociabilitat-solidaritat configurats entorn la percepcio "estar essencialment ben situat" i que, en conjunt, garantiria tant l'estabilitat comunitària com la pròpia existència i reproducció normativa.

\section{BIBLIOGRAFIA}

A.C.BHAKTIVEDANTA SWAMI PRABHUPADA.

1978 Bhagavad-Gita. Itàlia, Bhaktivedanta Book Trust.

BERGER, P.L./LUCKMANN, Th.

$1988 \quad$ La construcció social de la realitat. Barcelona, Herder.

GEERTZ, C.

1989 "La religión como sistema cultural", a La interpretación de las culturas. Barcelona, Gedisa.

HEBERT, G.

1978 Los testigos de Jehova. Su historia y su doctrina. Madrid, La casa de la Biblia, P.P.C.

JUST, C.M.

1989 Regla de Sant Benet. Publicacions de l'Abadia de Montserrat.

29 La resposta existencialista proporciona la seguretat vital necessària per transformar els més variats estats de dubte en solides guies normatives de finalitat transcendent, les quals, al seu torn, es tradueixen a la pràctica immediata en actituds decidides a culminar un projecte espiritual concret. Aixi, l'efectivitat primordial d'aquesta resposta radicaria en el fet que assegura, situa, omple, allibera (en forma de no subjecció i d'alteritat vivencial respecte a la condició materialista) i facilita, en suma, la "simbiosi automàtica" amb l'ordinaci6 $\mathrm{i}$ normativa institucional. Tal ordinació $\mathrm{i}$ normativa quedaria dissolta en el sistema de creences $i$, per tant, fusionada amb el mateix sentit de fe individual. 
POZUELO, F.G.

1990 "Hare Krishna: perspectiva sociológica", a Cuaderno de Realidades sociales, 35-36.

Las sectas en Espafia. Madrid, Instituto de Sociología Aplicada.

KNOWLES, D.

1969 El monacato cristiano. Madrid, Guadarrama.

TESTIGOS DE JEHOVA.

1983 Organizados para efectuar nuestro ministerio. Brooklin, New York, Watchtower Bible and Tract Society. Internacional Bible Students Asociation.

TONNIES, F.

1974 Comunidad y asociación. Barcelona, Península.

TURNER, V. W.

$1988 \quad$ El proceso ritual. Estructura y antiestructura. Madrid, Taurus.

\section{RAMACHARAKA.}

1991 Bhagavad Guita. El mensaje del maestro. Barcelona, Humanitas.

\section{VEDAVYASA DAS ADHIKARI.}

1983 Como llegar a ser vaisnava. Brihuega/Guadalajara, Edit. Bhaktivedanta. 